\title{
On a Paleontological Definition of the Genus Homo
}

\author{
Jean FRISCH \\ Sophia University, Tokyo
}

When discussing the problems connected with the origin of man one frequent source of confusion is the vagueness or ambiguity of the very concept of "man". This difficulty was clearly spelled out almost ten years ago by Le Gros Clark (1955) in his authoritative review of The Fossil Evidence for Human Evolution. Recent discoveries at Olduvai Gorge (Tanganyika) and the interpretation given to them (Leakey, Tobias \& Napier: 1964) show that the problem of defining the genus Homo is not solved yet and lies at the heart of much anthropological thinking.

The present communication constitutes an attempt at defining the genus Homo in a somewhat unusual way, namely by paying special attention to the evolutionary pattern believed to be proper to this genus. The central concepts of the following discussion, divergent and convergent evolution, are derived from the work of Teilhard de Chardin (1956) who however, to the writer's knowledge, did not refer to their possible import for hominid taxonomy.

The purpose of this communication is thus to formulate a working definition of the genus Homo, allowing the student of human evolution, the paleontologist in particular, to identify the time and the place of origin of this genus.

Distinguishing living members of the hominid and pongid families presents the taxonomist with no particular problem. The clear difference between the ranges of cranial capacities in both groups and the adaptation of the post-cranial skeleton to various ways of locomotion and body-stance clearly characterize each family. Similarly, the paleontologist found little difficulty in classifying fossil forms such as Java and Peking Man. Cranial capacity alone places them much closer to the family of man than to that of the great apes.

The discovery of numerous remains of Australopithecinae in South Africa during and after the Second World War raised a more delicate problem. Here were Primates with a surprizingly human looking post-cranial skeleton, indicating upright stance and gait, with a dentition likewise much closer to the human than to the pongid type (small incisors and canines), but with a brain size hardly, if at all, superior to that of the biggest among the great apes. Although brain size compared with estimated total body size places them above the living great apes, the absolute size differences are small indeed, especially if compared with the wide gap separating the low values of Australopithecinae from those of living or fossil hominids, including Java man (see Table I).

$$
-253-
$$


Table I. Cranial capacities of Pongids and Hominids, (all measurements in cc.)

\begin{tabular}{|c|c|c|c|c|}
\hline \multirow[b]{2}{*}{ Chimpanzee } & \multicolumn{2}{|c|}{ Representative Range* } & \multicolumn{2}{|c|}{ Total Range } \\
\hline & 350 & $\sim 450$ & 320 & $\sim 480$ \\
\hline Australopithecus & 450 & $\sim 550$ & 435 & $\sim 600$ \\
\hline Homo habilis & $(462$ & $\sim 723)^{\text {katk }}$ & & \\
\hline Pithecanthropus & 900 & $\sim 1,100$ & 775 & $\sim$ \\
\hline Homo sapiens & 1,200 & $\sim 1,500$ & 1,100 & $\sim 2,000$ \\
\hline
\end{tabular}

* The "representative range" includes the most common values and disregards aberrant cases.

** Estimation based on a single fairly well preserved specimen (Tobias, 1964).

The recent discoveries in Olduvai Gorge (Leakey \& Leakey, 1964) further contributed to close the gap between the brain size of living Pongids and Hominids. Regardless of the correct taxonomic status of the fossil form named by Leakey Homo habilis, we now possess a practically continuous series of fossil brains from the Chimpanzee to Modern Man, passing through the Australopithecus group, Homo habilis, the Pithecanthropus group (Java, Peking) and early fossil Homo sapiens. Where and how then should one draw the line determining the admission of a fossil form in the genus Homo?

Anthropologists anticipated this sort of difficulty many years ago, and several attempts were made at defining a new criterion for Homo. The best known and most clearly formulated attempt is perhaps that made by Dr. Kenneth P. Oakley $(1954,1957)$ of the British Museum. The author proposes the ability of tool-making as the decisive criterion for inclusion in the genus Homo. This proposal has received considerable acceptance among anthropologists.

While fully admitting the interest of this proposal, it may be remarked that the use of a behavioral, non-morphological criterion is not only uncommon in paleontology, but that the reliance on such a character as the main or even sole criterion for inclusion in a genus is simply unknown in taxonomic practice.

Furthermore, recent observations on wild primate behavior (Goodall, 1963) strongly suggest that there is as much continuity between the simple toolusing known in several mammals and purposeful tool-making as there is in the series of brain sizes. Dr. Oakley was probably aware of this difficulty when he added that only systematic tool-making (i. e. shaping tools according to a definite method and for a given purpose) was to be regarded as the hallmark of Homo, in as much as such activity provided evidence for conceptual thinking.

Such being the case it may be worthwhile to inquire whether pure morphological criteria are indeed unable to provide us with the kind of evidence here sought for, namely the evidence for the kind of activity universally recognized as proper to man: conceptual thinking, power of abstraction, true language.

Soon after the discovery of the skull cap of Java Man by Dubois in 1892 attempts were made at detecting on the brain-cast unequivocal signs of the use of true language. It is well known that these attempts, often reiterated since, have proved unconclusive.

The use of morphological evidence here proposed in order to assess intellectual activity is of an altogether different nature. It rests on observations familiar to 
all paleontologists and whose significance has been underlined and commented upon at length by Teilhard de Chardin in his work Le Groupe Zoologique Humain (1956).

The evolution of an animal phylum customarily occurs by way of progressive differentiation between the branches composing the phylum, each of them adapting to the exploitation of a particular section or aspect of the habitat available to it. This phenomenon, called adaptive radiation, accounts in modern evolutionary theory for the multiplication of genera and species within each phylum, as well as for the peculiar specializations proper to each animal form. This pattern of evolution is called by Teilhard "diverging evolution". It can be observed in the history of all animal phyla and is particularly marked at the origin of novelties in the history of life, v.g. at the origin of land vertebrates, of the mammals, etc.

There is no reason why the origins of the hominid faminid family should have been different or have missed this characteristic. As a matter of fact, the large morphological differences between the two types of Australopithecinae known from South Africa (Australopithecus, Paranthropus) indicate that the process of diverging adaptation was at work in the newly arisen family as well as in all others.

The next stage of hominid evolution however, corresponding roughly to the Pithecanthropus forms of the Far East, reveals a different picture. Although the finds belonging to approximately the same age in other regions of the world are still too scarce to allow a clear-cut judgment, it is important to note that all the available evidence (Ternifine in North Africa, Olduvai in East Africa, Mauer in Europe) points to similarities with the Far Eastern specimens and to the absence of such marked differences as are observed in South or East Africa between hominids living in one much narrower region.

This tendency towards greater uniformity between contemporary hominid forms as one progresses in time seems furthermore to have increased until the present time. The populations contemporary of Western Europe's Neanderthal Man vary considerably more in their morphology than later specimens of local varieties of Homo sapiens. Even if Dobzhansky (1944) is correct in assuming that only one species of fossil man ever existed on earth at any given time, it seems clear that the variety of people was much greater 100,000 years ago than it is now. In other words, the available fossil evidence indicates that human evolution has been following a converging pattern rather than the diverging one common to all other animal phyla.

A double reason can tentatively be proposed for this peculiarity of the hominid pattern of evolution. First, the development of technology has made it more and more unnecessary for man to rely on morphological differentiation for adapting to various environments. Material cuture and development of a body of technical knowledge has created an increasingly efficient buffer between man as an organism and the environment. Man's adaptation is more and more of his own making and does not have to wait for favorable gene mutations or combinations to occur. This switch from selection-made to man-made adaptation results of course in a 
much less pronounced trend towards morphological differentiation, although the trend is not absent and was probably more intense in technologically less advanced societies.

While this first factor accounts reasonably for the absence of excessive morphological differentiation, it does not explain why differences tend to become reduced, why a converging type of evolution succeeds to the former diverging type. This latter phenomenon results, it can be assumed, from increasing communication between heretofore largely separated groups of people. Increased facilities in travelling, but especially, and fundamentally, the ability to communicate through language with neighboring tribes resulting in mutual understanding and intermarriage would not only prevent any further genetic separation but positively foster the breaking down of already extant genetic differences. The morphological uniformisation process resulting from this increasing communication can be observed taking place to-day in several parts of the world. Should communication further increase in the next centuries, as is most likely, this explanation should lead us to expect increasing racial amalgamation.

It will be noticed that both factors here proposed in order to account for the particular evolutionary pattern proper to the genus Homo express the appearance of the faculty for conceptual thinking which is also responsible for the systematic tool-making adopted as criterion by Oakley. In the present perspective, however, the recognition of this faculty does not depend on archaeological findings but on the examination of the evolutionary pattern as expressed in the fossil record. The transition from the pre-human (before Homo) to the human (i. e. Homo) stage of evolution is defined as the transition from the diverging to the converging type of hominid evolution. This is because, if our interpretation is correct, the reversal of evolution's direction is due to the appearance of an animal capable not only to modify its environment but also to communicate with its fellows and desirous to remain or become united with them. Following this line of reasoning, the key-characteristic of the genus Homo would be not so much the technological skills (Homo faber) but rather the capacity to tie relationships with his fellowmen (Homo communicans).

Among the merits of the criterion here proposed for the definition of the genus Homo one should stress first of all that is is more meaningful from an evolutionary viewpoint than any isolated trait or constellation of isolated morphological traits, since it expresses the fundamental originality not only of a given organism but of the evolutionary pattern of the genus as a whole. The reversal of evolution's direction observed in the history of the phylum marks a clear break in the history of life, a break of unprecedented nature. We are witnessing here not merely one of the momentous "break-throughs" such as the conquest of land by the first tetrapodes or the development of placental reproduction in mammals, but a true revolution in the course of life's history.

Furthermore, the criterion here proposed, in distinction from the toolmaking ability proposed by Oakley, can be made the object of paleontological research. More intesive paleontological work will make it increasingly possible to determine 
exactly the point where hominid evolution switched from the diverging to the converging phase. The application of the criterion requires examination of the entire hominid record so that the classification of a given find as Homo rests primarily on its position in the whole picture of hominid history. To this end, absolute age determination for each find is of couse of capital importance.

For the time being the still fragmentary nature of the available fossil evidence allows only the definition of a broad time-level during which hominization took place. Beyond this zone the effects of converging evolution can clearly be detected, below this zone diverging trends are still observed. As our knowledge of the fossil record becomes more complete and as the available evidence is more carefully studied (especially as regards the chronological position of each form and the amount of morphological variability proper to it), this zone of hominization, now still very wide, can be expected to narrow down progressively. It is more than likely, however, that the clear dividing line between the pre-Homo and the Homo stages well always remain for the human paleontologist a limit to be aimed at, and one directing further research, but never reached.

It can thereby be seen that the adoption of the criterion here proposed, while not susceptible of an automatic application, provides a framework for the interpretation of past and future discoveries. It acts as a dynamic concept, reflecting the dynamism of the process it aims at understanding better.

\section{Bibliography}

Dobzhansky, Th.

1944 On Species and Races of Living and Fossil Man. Am. Journ. Phys. Anthr., n.s. 2: 251-265.

Goodall, J.

1963 Feeding Behaviour of Wild Chimpanzees. In Symposia of the Zoological Society of London, n. 10: The Primates, pp. 39-48.

Leakey, L. S. B., P. V. Tobias \& J. R. Napier

1964 A New Species of the Genus Homo from Olduvai Gorge. Nature: 202, 7-10.

Leakey, L. S. B. \& M. D. Leakey

1964 Recent Discoveries of Fossil Hominids in Tanganyika at Olduvai and Near Lake Natron. Nature: 202, 5-7.

Le Gros Clark, W. E.

1955 The Fossil Evidence for Human Evolution. University of Chicago Press.

Oakley, K. P.

1954 Skill as a Human Possession. In A History of Technology, C. Singer et al., eds. London, Oxford University Press. Vol. 1, pp. 1-37.

1957 Tools Makyth Man. Antiquity: 31, 199-209.

Teilhard de Chardin, P.

1956 Le Groupe Zoologique Humain. Paris, Albin Michel.

Tobias, P. V.

1964 The Olduvai Bed I Hominine with Special Reference to its Cranial Capacity. Nature: $202,3-4$. 